\title{
RESSIGNIFICAÇÃO DA EDUCAÇÃO RURAL NA EXPERIÊNCIA DO MOVIMENTO DOS TRABALHADORES RURAIS SEM TERRA (MST) NO ESTADO DO PARANÁ: O CASO DAS ESCOLAS ITINERANTES ${ }^{1}$
}

\author{
Beate Jungemann ${ }^{2}$ \\ Francis Mary Guimarães Nogueira ${ }^{3}$
}

\section{RESUMO}

O Movimento dos Trabalhadores Rurais Sem Terra (MST) do Brasil luta por uma educação escolar autônoma, articulada à luta por uma Reforma Agrária Popular. As Escolas Itinerantes são a expressão do processo de ressignificação da escola rural mediante as práticas políticas desde sua criação em acampamentos no Estado do Paraná. Representam um avanço importante na materialização de outra concepção educacional em construção a partir da vida concreta das comunidades organizadas nas terras ocupadas. As negociações com o Estado do Paraná pela legalização das Escolas Itinerantes e a aceitação de seu Projeto Político Pedagógico significam uma conquista de suas reivindicações pelo direito a uma educação do campo autônoma. Ao mesmo tempo, implicam o começo de um controle burocrático-legal por parte do poder público estatal, que aumenta com a transição do acampamento para o assentamento. Nesse processo transitório, as Escolas Itinerantes se convertem em escolas públicas estaduais e municipais criando novos desafios para o MST, devido à problemática da ressignificação da escola rural em escola do campo.

Palavras-chave: Ressignificação de política de educação rural; MST Brasil; Escolas Itinerantes; estado do Paraná.

\section{REFRAMING RURAL EDUCATION BASED ON THE LANDLESS WORKERS MOVIMENT (LWM) EXPERIENCE IN PARANÁ STATE: THE CASE OF ITINERANT SCHOOLS}

\begin{abstract}
The Landless Workers Movement (LWM) in Brazil has striven for an independent school education, which should be associated to some struggle aiming a Popular Agrarian Reform. The Itinerant Schools are the reframing process expression of rural school by the political practices since their inception in camps in Paraná state. They represent an important breakthrough to achieve a new educational concept under development based on the real life of organized communities in occupied lands. Negotiations with Paraná State in order to legalize the itinerant schools and accept their Political Pedagogical Project mean an achievement of their demands for the right to an autonomous education in rural area. At the same time, they imply the start of a bureaucratic-legal control by the State power that increases with the transition from a camp to a settlement. In this transitory process, Itinerant Schools become State and municipal Public Schools consequently there come new challenges for LWM, due to the redefinition process from rural school to a field one. Keywords: Redefinition of rural education policy; Brazil LWM; Itinerant Schools; Paraná State.
\end{abstract}


Esta cova em que estás, com palmos medida, [...] é a parte que te cabe neste latifúndio. João Cabral de Melo Neto

\section{INTRODUÇÃO}

Muitos dos movimentos sociais que emergiram na América Latina, como consequência dos impactos das políticas neoliberais nas condições de vida dos setores pobres urbanos e rurais, lutam por uma apropriação de espaços territoriais para recuperar e/ou experimentar formas de viver e de produzir em comunidade. Trata-se de práticas orientadas em direção a uma maior autonomia frente ao Estado e ao mercado (JUNGEMANN, 2008, p. 1-34). O Movimento dos Trabalhadores Rurais Sem Terra (MST) representa claramente essa orientação em seu projeto de transformação social e territorial a curto, médio e longo prazo (MANÇANO, STEDILE, 2003). Desenvolve estratégias nacionais e estaduais há mais de 20 anos com uma posição de enfrentamento que pressiona o Estado para atingir seus objetivos gerais de uma Reforma Agrária com justiça social que inclua o direito a uma Educação do Campo, rompendo com o conceito de educação rural.

A Educação do Campo no Brasil ainda é uma educação em construção que, apesar de sua existência relativamente curta como conceito e política pública ${ }^{4}$, tem algumas experiências materializadas nos territórios de resistência e configurações sócio-históricas concretas como são as Escolas Itinerantes dos acampamentos do MST.

A Educação do Campo, principalmente como prática dos movimentos sociais camponeses, busca conjugar a luta pelo acesso à educação pública com a luta contra a tutela política e pedagógica do Estado (reafirma em nosso tempo que não deve ser o Estado o educador do povo) (CALDART et al., 2012b, p. 264).

A maior força em direção à autodeterminação e maior independência frente ao Estado constitui a luta do MST pela terra, com a finalidade de ter o controle sobre esta para garantir subsistência das famílias campesinas afetadas e expulsas do campo como consequência da modernização capitalista do setor agrícola e do efeito das políticas neoliberais em nível rural. Essa luta pela terra desde os anos 1980 está intrinsecamente articulada à construção de "um controle territorial organizado em torno das estruturas de poder popular" (VERGARA CAMUS, 2011, p. 10). Esse controle territorial tem várias dimensões: uma expressamente sócio-territorial, relacionada ao desenvolvimento organizado e político participativo, educativo e produtivo, e outra político-institucional, referida à relação com o Estado e o poder político e, desse modo, à incidência na política pública.

A dimensão político-institucional compreende a institucionalização do Movimento entendida não como cooptação, mas como processo necessário do movimento tático da política organizacional, mediante distintas formas de articulação com o Estado e orientada principalmente em direção a redefinição de políticas públicas. Conceitualmente, entende-se políticas públicas como ação delibera de Estado vinculadas estruturalmente a formas específicas de relações de poder, de produção, de reprodução social e de propriedade existentes em uma sociedade num momento histórico dado. As relações de poder por sua vez se expressam em uma estrutura territorial (urbana, rural) e político-administrativa 
determinadas regiões, estados e municípios, onde entram em disputa distintas lógicas e interesses pelo controle territorial.

Quando falamos de ressignificação ${ }^{5}$ da Educação Rural pelo MST nos referimos às transformações introduzidas, de forma protagônica, pelo Movimento na política pública a partir de sua luta social autônoma dos territórios (acampamentos e assentamentos), mais que ao mesmo tempo significa entrar em uma lógica de institucionalização por inserir-se nas estruturas de tomada de decisões do Estado, pelo direito à educação pública. Essa institucionalização não é entendida como cooptação, mas mais precisamente como processo necessário de aprendizagem política, tática e organizacional, mediante distintas formas de articulação com o Estado e orientada principalmente em direção a uma redefinição de políticas públicas. No caso das Escolas Itinerantes, se trata de uma luta pelo reconhecimento legal de um direito legítimo e universal, na qual o MST mantém sua autonomia relativa a partir de sua posição política contra-hegemônica de luta pela terra. Seu objetivo, a longo prazo se projeta em uma Reforma Agrária Popular que requer dentro do Estado mudanças estruturais e de funcionamento de suas instituições ${ }^{6}$.

Para discutir essa proposição, esse artigo está constituído em três partes: a primeira descreve o contexto histórico que explica a emergência da Educação do Campo como uma reivindicação política de muita relevância no Brasil, na qual se inscreve a Escola Itinerante do MST, que é o tema central do segundo ponto; a terceira parte trata da inserção da Escola Itinerante no sistema educativo do estado do Paraná. Por último, apresentamos algumas reflexões como conclusões provisórias dessa parte pesquisa.

\section{BREVE CONTEXTUALIZAÇÃO HISTÓRICA DA EDUCAÇÃO DO CAMPO NO BRASIL}

A história da luta pela terra no Brasil remonta ao início da colonização. A partir dessa época, as estratégias no enfrentamento de classe tomaram formas e dimensões jurídico-políticas distintas na repressão, na eliminação física, associando outras estratégias mais sofisticadas de criminalização dos Movimentos Sociais Populares do Campo por parte das oligarquias e, posteriormente, pelas diferentes frações da burguesia. As lutas campesinas nos anos de 1950 já denunciavam e anunciavam na Região Nordeste a penetração do capital no campo, e com a "Revolução Verde" as características dos antigos latifúndios adquiriram novas formas de concentração da propriedade da terra. A produção de algumas commodities nesses "novos" latifúndios estava especificamente orientada para a exportação ao mercado externo. O golpe Civil-Militar de 1964, praticamente destruiu todos os movimentos contestatórios que haviam emergido entre 1950 e 1964, entre eles os campesinos nordestinos. Mas permaneceu na memória dos pequenos agricultores, arrendatários e dos "boias frias", deslocados para as pequenas, médias e grandes cidades, a história de como ocorreu a expulsão do campo naqueles anos. Ainda em pleno Regime Militar emergiu no seio da Igreja Católica uma parcela progressista de padres, bispos, arcebispos e cardeais que organizou, em nome da Teologia da Libertação, diversos movimentos católicos como a Comissão Pastoral da Terra (CPT), Pastoral Rural e da liturgia do "Deus encarnado no homem concreto" - Comunidades Eclesiais de Base- CEBs. Esses distintos grupos pastorais atuavam na ação política dessas Comunidades, engajados nas necessidades dos pobres das periferias e do campo ${ }^{7}$. No início dos anos 1980 , com a eclosão de outros Movimentos Sociais Populares de distintas ordens, ganha outro vigor político, a luta pela terra com a criação do MST. O Movimento se constituiu no ano de 1984, no oeste do estado do Paraná, no município de Cascavel ${ }^{8}$. 
A questão agrária reaparece como um dos problemas estruturais da desigualdade social brasileira no processo de redemocratização, colocando outra vez em debate o atrasado projeto das elites brasileira. Desde sua emergência, o MST estabeleceu como seus objetivos a luta pela ocupação da terra, pela Reforma Agrária e pela transformação social. Define-se como "um movimento social, de massas, autônomo, que procura articular e organizar os trabalhadores rurais e a sociedade para conquistar a Reforma Agrária e um Projeto Popular para o Brasil” (KNOPF, 2013, p. 57).

Como resposta ao crescimento organizado do MST e de sua militância em todo o Brasil, a repressão do Estado burguês assumiu muitas facetas em nível nacional, incluindo o estado do Paraná

[...] pois os governos Richa (1983 a 1986) e Álvaro Dias (1987 a 1990), ambos do PMDB, usaram de várias estratégias para acabar com a organização do MST: despejos, repressão policial, descumprimento de acordos, agressão verbal (MST, 2008a; MST, 2008b). Em 1987, por exemplo, no governo Álvaro Dias, 750 famílias foram violentamente despejadas da Fazenda Corumbatã, por mais de mil soldados, fortemente armados com metralhadoras e gás lacrimogênio (MST, 2008a). Apesar da pressão, o Movimento não retrocedeu. Muitas ocupações foram feitas no período. Em 1987 e 1988 o processo de ocupação foi intenso (SAPELLI, 2013, p. 67-89) ${ }^{9}$.

A luta pela terra se une à luta por uma educação pública e gratuita em todos os níveis. Nos últimos anos da ditadura e nos primeiros anos da redemocratização, os sindicatos de professores, as associações acadêmicas, a Sociedade Brasileira para o Progresso da Ciência, e a União Nacional de Estudantes (UNE) começam a se pronunciar pela democratização da educação. Nesse contexto, surge a reivindicação pela Educação do Campo ${ }^{10}$ como um direito a uma educação autônoma por parte de movimentos sociais que lutavam pela terra e por uma mudança das condições de exclusão, expulsão e exploração extrema da população rural $^{11}$ (campesinos, indígenas, pescadores, quilombolas e os afetados pelas represas).

Nesse sentido, a Educação do Campo nasce das práticas de luta pela terra e dos direitos sociais e econômicos não voltados para a inclusão social na sociedade capitalista existente - enfoque representado pela concepção oficial da Educação Rural das instituições do Estado -, mas orientada para a transformação dos sujeitos sociais do campo num horizonte de mudanças do modelo de capitalismo agrário. Para tanto, o MST promove num processo de centenas de ocupações da terra, em todo o Brasil, e, particularmente, no Paraná a ressignificação da Educação Rural ${ }^{12}$ por meio da materialização de uma Educação do Campo autônoma.

Desde o começo, a compreensão da Educação do Campo incluía a reivindicação pela autonomia para a definição de concepção e conteúdos pedagógicos na forma de ensinas, relacionado ao conhecimento do direito pelas distintas visões, lutas, práticas e formas organizativas no plano social, produtivo e cultural das populações do mundo campesino em especial e rural em geral (CALDART, 2012, p. 259-260).

As primeiras reflexões sobre a necessidade de uma educação escolar distinta do campo impulsionaram o desenvolvimento de uma outra concepção de Escola, que não estivesse no perímetro urbano, reivindicando ao mesmo tempo o caráter político para a transformação das condições sociais e econômicas da classe trabalhadora no campo, no sentido de transformação das relações de poder existentes. O MST, como movimento de massa, conseguiu viabilizar a necessidade de uma formação humana emancipadora como 
alternativa para a escola capitalista a partir das contradições que definem a questão agrária no Brasil. A Escola Itinerante ${ }^{13}$ é uma expressão avançada da materialização desse novo paradigma educativo em contínua construção.

\title{
EMERGÊNCIA DA ESCOLA ITINERANTE E SUA CONSOLIDAÇÃO NO ESTADO DO PARANÁ
}

O objetivo de ter um espaço que respondesse às necessidades escolares de crianças, adolescentes e adultos das famílias dos trabalhadores Sem Terra, data desde a instalação dos primeiros acampamentos e assentamentos do MST no final dos anos de $1980^{14}$.

\begin{abstract}
A Escola Itinerante, nos seus grandes objetivos, foi criada para atender a crianças, adolescentes, jovens e adultos em situação itinerante, enquanto estão acampados lutando pela desapropriação das terras improdutivas e pela implantação do assentamento. É uma Escola que, na sua essência, não está voltada somente para as crianças, mas para toda a população acampada, jovens, idosos e adultos, pois os acampamentos são formados por famílias que não só foram excluídas da terra, mas também foram excluídas do processo produtivo e de todos os seus direitos, inclusive o de estudar (GEHRKE, GREIN, 2008, p. 88).
\end{abstract}

Em novembro de 1996, o Conselho Estadual de Educação do estado do Rio Grande do Sul aprovou as primeiras experiências educativas do Movimento dentro de um projeto chamado "Experiência pedagógica - Escola Itinerante para acampamentos de reforma agrária do Rio Grande do Sul" (FACCIN WEIDE, 2009, p. 9-26). No ano de 2002 essa experiência estadual foi reconhecida legalmente de maneira definitiva como primeira E. I. do MST em nível nacional depois de um longo tempo de negociação e enfrentamento entre o Setor de Educação do Movimento e a Secretaria de Educação do Estado ${ }^{15}$. Essa nova reivindicação do MST serviu como argumento legal e político, para pressionar outros estados e entidades federais na busca pela legalização das escolas em seus respectivos acampamentos, como é o caso das E.I. do estado do Paraná ${ }^{16}$.

A luta pela terra no Paraná, onde se enfrentam o Estado, a burguesia agrária organizada e diferentes movimentos de luta pela terra, historicamente foi muito intensa. Os anos de 1990 foram marcados por muitos e graves conflitos agrários tanto em nível nacional ${ }^{17}$ como estadual - neste especialmente durante o período do governador Jaime Lerner (1995 e 2002). Entre 1994 e 1999 as ocupações de terra e manifestações eram constantes no Paraná. Uma das maiores ocupações realizadas foi a da Fazenda Pinhal Ralo, no Rio Bonito do Iguaçu, dia 17 de abril de 1996; propriedade da empresa GiacometMarodin, com uma extensão de 83 mil ha. Foi considerado o maior acampamento da América Latina porque durante um ano acamparam 13.276 famílias na fazenda, das quais 3.081 conseguiram assentar-se entre 1997 e 1998 em 4 assentamentos, com um total de 16.852 ha de terra desapropriada (MORISSAWA, 2001; SAPELLI, 2013). Durante toda a gestão do governo Lerner houve mais de 15 mortos e mais de 250 militantes do MST presos. (MANÇANO, STEDILE, 2003).

A trajetória da E. I. no estado do Paraná se destacou nesse panorama de conflitos pela terra. Segundo o Caderno da Escola Itinerante (MST, 2008a), seu primeiro surgimento data de 1999 quando em junho desse ano as famílias de um acampamento instalado diante do Palácio do Iguaçu, em Curitiba, ocuparam um edifício governamental abandonado para organizar atividades escolares. A ocupação tinha como objetivo protestar contra as repressões e perseguições ao MST por parte do governo estadual, contra o lento avanço da 
Reforma Agrária e, sobretudo, pressionar publicamente o estado para obter uma resposta política contra a discriminação escolar e a exclusão ao direito a uma educação pública e gratuita para as crianças das famílias acampadas. Essa experiência de ocupação foi batizada pelo Movimento como "Primeira Escola Itinerante no estado do Paraná", ainda que sua formatação legal, como projeto de Educação do Campo, somente tenha ocorrido em 2003/2004 por meio do qual se aprovou a criação de um tipo particular de escola nos acampamentos, no contexto de sua inserção político-institucional ao sistema educativo estadual $^{18}$.

No momento em que Luiz Inácio Lula da Silva (PT) ganhou as eleições presidenciais em 2002 e assumiu a presidência em janeiro de 2003, o MST publicamente apoiou publicamente Lula. No estado do Paraná, o Movimento foi fortalecido pela "aproximação amistosa" do governador eleito, Roberto Requião, do PMDB, que como Lula governou durante duas gestões (2003-2006 e 2007-2010). Essa correlação de forças mais favorável abriu espaço para que iniciasse o processo de negociação entre o MST e o estado do Paraná pela legalização da E. I. ${ }^{19}$. Para além do direito constitucional de acesso à educação pública, a legitimidade do Movimento exigia uma definição de governo. No entanto, apesar da possibilidade de diálogo, as tensões foram permanentes, como explica um dos Coordenadores do Setor de Educação Estadual do MST do Paraná.

Nesse período se explicitou a necessidade de escola em grandes
acampamentos. Então a gente tinha em Quedas do Iguaçu 2
acampamentos, um com 800 e outro com 1200 famílias. As crianças, os
estudantes lá, não tinham vagas na escola. Então isso colocou para o
Estado uma necessidade de pensar o atendimento desses sujeitos no
acampamento. Então o Estado do Paraná viu a escola itinerante como
uma forma de atender emergencialmente essa necessidade, mas nós do
movimento vimos a partir disso... quando cria a escola, que foi o próprio
movimento que foi formulando ela nas práticas dos acampamentos.
Assim, foi uma proposição do próprio movimento de criar essas escolas
como alternativa e para o Estado era para solucionar o problema rápido.
Mas nós tínhamos clareza do que a gente queria com aquela escola, que é
a possibilidades da gente poder colocar em funcionamento, garantir o
acesso a educação nos moldes ou na perspectiva do movimento
(Entrevista a Alessandro Mariano, 25.09.12).

A visão reivindicativa por uma educação pública nos acampamentos do MST não se limita a uma lógica política setorial, mas se inscreve na luta e disputa territorial contra os latifundiários e o Estado a partir de uma ocupação da terra. Nessa lógica, contrahegemônica se fundamenta a necessidade de uma educação autônoma reivindicada como direito a uma política pública. Essa tensão entre autonomia e institucionalização caracteriza a relação contraditória que tem o MST com o Estado defendendo os interesses da classe trabalhadora em um horizonte de luta por uma Reforma Agrária e de Poder Popular. A E. I. nasce com o acampamento, quer dizer, com a ocupação da terra, que implica luta, resistência e subsistência econômica. $O$ acampamento se concretiza como uma comunidade grande onde as famílias constroem novas relações e formas de organização social, comunitária e de produção, desenvolvendo uma identidade tanto militante coletiva, como territorial, na itinerância antes de serem assentadas. Essas novas condições de convivência configuram a organicidade de cada acampamento, materializada de maneira muito diferente no tempo e nos territórios concretos ocupados, mas correspondendo a uma 
estrutura organizativa de base comum e uma dinâmica de intercâmbio descentralizado nos distintos níveis e instâncias do Movimento ${ }^{20}$.

O fortalecimento organizacional e o futuro do desenvolvimento dos acampamentos estão direta e indiretamente relacionados à concepção da E. I. acerca do papel dos alunos e da formação dos educadores do Movimento. Na maioria dos casos é a comunidade que constrói os espaços da escola com materiais básicos, com auxílio ou não do Estado; as reconstrói na necessidade da intinerância, e as mantém no tempo que dura a ocupação.

Os desafios educativos do MST manifestos no começo da constituição do Movimento seguem sendo enormes: definir o tipo de escola que realmente se quer e para que tipo de sociedade e de produção; como vincular e incluir de maneira mais organizada as famílias das comunidades na "construção social e político-ideológica" da escola e como garantir uma comunicação e direção mais horizontal entre os diferentes níveis organizacionais do MST em relação à construção do modelo escolar e pedagógico ${ }^{21}$.

A decisão das famílias de viver em um acampamento do MST significa que estão dispostas a construir um futuro comum a partir da conquista da terra e uma vida digna compartilhada em comunidades organizadas com regras de convivência estabelecidas e controladas com autonomia pela coletividade ${ }^{22}$. Viver em coletividade é um processo de aprender a viver de forma comunitária, de construir identidade e solidariedade. Nos acampamentos se juntam famílias de trabalhadores cujas origens e experiências de vida são similares porque muitos lutaram juntos, mas também são diferentes tanto em relação a sua condição de exclusão como no que diz respeito a sua cultura, sua socialização e educação ${ }^{23}$. Por conseguinte a relação entre comunidade e escola não está livre de conflitos que podem ser causados por diferentes visões da comunidade sobre o papel da escola e do funcionamento desta.

Outro desafio do MST é enfrentar a contínua falta de resposta do Estado à Reforma Agrária e com isso a luta pela constituição de assentamentos. Muitas famílias acampadas passam até sete ou mais anos em condições extremamente difíceis sem ter um horizonte temporal definido sobre o momento de serem assentadas. Segundo Sapelli (2013), se registra uma diminuição do número de habitantes na maioria dos acampamentos do estado do Paraná onde existem condições de produção agrícola demasiado precárias que dificultam inclusive chegar a um nível de subsistência familiar ${ }^{24}$.

Contraditoriamente, as experiências educativas registradas e analisadas pelo MST no estado do Paraná mostram que nessas circunstâncias precárias e de resistência nos acampamentos a E. I. encontra espaço e força para avançar como projeto político pedagógico (KNOPF, 2013).

Precisamente, o Projeto Político Pedagógico (PPP) da Escola Itinerante é a expressão das reflexões sobre a troca de experiências escolares nos territórios concretos onde a vida cotidiana é um processo de socialização política e coletiva contínuo baseado na compreensão das contradições em que vive a classe trabalhadora, nesta sociedade. $\mathrm{O}$ ensino é orientado para a transformação da realidade, vincula a teoria com a prática, preparando para o trabalho e o exercício de cidadania, caminho para o desenvolvimento de um novo sujeito. Essa socialização e conscientização está registrada nos conteúdos, práticas pedagógicas, métodos avaliativos e formas de autogestão da Escola Itinerante ${ }^{25}$.

E criar espaços onde educandos de todas as idades possam experimentar a organização e a vivência real de sua autonomia, de sua capacidade de coordenar e ser coordenado, de crítica, autocrítica e proposição, entre outras. Isso é permitido quando a escola se organiza em núcleos de base, brigadas, equipes de estudo e trabalho, oficinas, assembleias, conselhos de classe participativos, entre outros. Estes são alguns dos espaços já 
conhecidos e experimentados, porém precisam ser potencializados. A construção de tais tempos e espaços na escola implica em planejá-los com intencionalidade, mas também envolvendo o educandos e a comunidade (GEHRKE, GREIN, 2008, p. 92).

Com essa concepção de Escola, a valorização da vida coletiva acima dos interesses particulares adquire uma força que envolve os estudantes desde os primeiros anos em experiências participativas e de tomada de decisões comuns. Esse avanço na configuração de relações menos verticais é uma parte intrínseca de um processo de construção de poder popular em territórios ocupados a partir de suas estruturas organizacionais e práticas participativas. Reconhecer a importância da E. I. no processo significa entender que seu papel é mais que ser uma política pública diferente, é contribuir para a construção de uma nova territorialidade. Não significa, que ainda não há um caminho longo a ser percorrido para transpor as muitas limitações.

Em síntese, o primeiro período do governo Requião (2003-2006), o MST buscava a legalização da E.I para poder ter direito de fato a uma educação autônoma e, por conseguinte, à inserção no Sistema Escolar Público Estadual. No segundo período desse mesmo governo (2007-2010), o MST se preocupou mais em consolidar a escola nos acampamentos, ampliando a oferta dos níveis de ensino e avançar na relação entre a prática escolar comunitária e o processo produtivo vivenciado nos acampamentos, nas discussões teóricas sobre a proposta política pedagógica dessa escola, como alternativa à escola capitalista (KNOPF, 2013).

A seguir, apresentamos como se desenvolveu até agora a inserção institucional da E. I. como modalidade de uma Educação do Campo e as contradições presentes nesse processo.

\section{A INSERÇÃO POLÍTICO-INSTITUCIONAL DA ESCOLA ITINERANTE NO SISTEMA EDUCACIONAL DO PARANÁ}

Não é demais reafirmar, que a luta pela terra e pela escola vem se entrelaçando desde a criação do MST. A reivindicação pelas bases legais da Educação do Campo tem sua referência na Constituição do Brasil de 1988, que garante a igualdade de condições de acesso e permanência na escola (Art. 206, inciso I). Posteriormente, em 1996, a Lei de Diretrizes e Bases da Educação Nacional (LDBEN) no 9.394/1996 se refere ao direito da população rural à Educação Básica. Como anunciado acima, entre os anos 1990 e o começo de 2000 foi um tempo marcado pela luta dos Movimentos Sociais por uma Educação do Campo autônoma. A aprovação da LDBEN permitiu a criação de várias políticas sociais para a educação no campo, como é o caso do Programa Nacional de Educação na Reforma Agrária (PRONERA) ${ }^{26}$, que contava com a ativa participação do MST. No ano 2002, o Conselho Nacional de Educação (CNE), em sua Câmara de Educação Básica (CEB), aprovou a Resolução 1, que instituiu as Diretrizes Operacionais para a Educação Básica nas escolas do campo, fazendo referência à criação de coordenações próprias de Educação do Campo nas Secretarias de Educação dos estados federados. Em 2004, se criou no Ministério de Educação (MEC) a Coordenação Geral de Educação do Campo e quatro anos depois, em 2010, o CNE-CEB aprovou a Educação do Campo como uma das modalidades da Educação Básica (Resolução n 4).

Como resposta à exigência do MEC, no Paraná, o governo Requião, com certa disposição, negociou com o MST e institucionalizou a Educação do Campo mediante sua incorporação à Secretaria de Educação Permanente, Alfabetização, Diversidade e Inclusão (SECAD), criada em 2005. Em um momento anterior, o Conselho Estadual de Educação 
(CEE) aprovou o Parecer $n^{\circ}$ 1012/2003, que favoreceu a autorização da criação das Escolas Itinerantes e, na sequência, a Resolução n ${ }^{\circ}$ 614/2004 da Secretaria Estadual da Educação do Paraná (SEED-PR) autorizou a implementação de Escolas Itinerantes nos acampamentos e assentamentos do MST.

Essa conquista política e legal a favor das E. I. no Paraná propicia um certo controle da burocracia escolar e pedagógica, mas também impõem ao Estado novos requerimentos formais a serem resolvidos no plano das obrigações institucionais. Essas exigências incluíam o financiamento das E. I. e, associado a este, a responsabilidade pelas documentações escolares dos alunos. A questão do financiamento das escolas foi solucionada por meio da Resolução $\mathrm{n}^{\circ}$ 614/2004. A respeito das exigências legais e pedagógicas, a Resolução ${ }^{\circ}$ 1660/2004 da SEED-PR autoriza o Colégio Estadual Iraci Salete Strozak, na categoria de Escola Base $^{27}$, a ser responsável pelo registro, arquivamento e a expedição da documentação escolar dos alunos de todas as E. I. da Educação Básica. Todo esse marco legal obriga o estado a pagar mensalmente os professores que trabalham nas escolas dos acampamentos e distribuir ali os alimentos, livros e materiais didáticos. O cumprimento desses deveres do Estado que permitem pelo menos o mínimo funcionamento das E. I. depende em grande parte de contínuas e diversas ações de pressão por parte do Movimento.

O MST do estado do Paraná enfrenta dois grandes desafios de curto e médio prazo: i) garantir a implementação da proposta político-pedagógica, discutida e adotada pelas escolas, que já está autorizada como projeto pelo Conselho Estadual de Educação do Paraná (Parecer $n^{\circ}$ 1012/2003) (MST-PR, SEED-PR, 2009), e ii) assegurar a presença dos professores necessários para todos os níveis de ensino nas E. I. dos acampamentos. Em geral, os educadores responsáveis pela Educação Infantil e dos primeiros anos do Ensino Fundamental são acampados do MST. Os professores dos últimos anos do Ensino Fundamental e os do Ensino Médio são oriundos da rede estadual de educação e são selecionados sob as exigências estabelecidas pela Secretaria Estadual de Educação.

Desde a criação legal das E. I., o estado do Paraná, por intermédio da SEED-PR, e a Associação de Cooperação Agrícola e Reforma Agrária do Paraná (ACAP), como fundação, coordenada pelo MST, estabelece Convênios de Cooperação Técnica e Financeira para assegurar a presença de professores das séries iniciais e finais do Ensino Fundamental e do Ensino Médio nas escolas. A SEED-PR cumpre sua responsabilidade mediante a contratação de professores via Processos de Seleção Simplificados (PSS). A garantia da contratação dos educadores, particularmente para a Educação Infantil e os primeiros anos do Ensino Fundamental, e a orientação pedagógica e organizacional própria do MST expressam as conquistas e o grau de autonomia do Movimento frente ao Estado.

O processo de coordenar a escola é o processo político e pedagógico da escola... é nosso. Somos nós que damos as linhas... Eles sabem que nos temos uma intenção com a escola, porque a escola tem uma intenção. Então, eles tentam pegar a gente pela burocracia para fazer a gente desistir da escola. Então a gente vai para a luta. Se eles não mandarem merenda, nos vamos atrás de comida aqui nas famílias. Nós não deixamos de ir para escola porque não tem merenda (Entrevista a Geni Teixeira, Dirigente Política da Brigada Teixeirinha, Assentamento Valmir Motta de Oliveira, Cascavel. 13.09.12).

Porém, como parte e resultado da própria luta pelo reconhecimento legal das E. I., emerge mais uma contradição no processo da transição do acampamento ao assentamento. Essa nova realidade ganha expressão, quando a E. I. se torna escola pública do estado do 
Paraná e/ou escola pública do município onde ela está localizada. O caso emblemático é a Escola Zumbi dos Palmares, a qual oferece o Ensino Fundamental, que é responsabilidade do município de Cascavel, e o Ensino Médio, que é responsabilidade do estado do Paraná. O processo de transição indica por um lado um avanço no processo de autonomia do MST frente ao Estado, conquistado pela luta permanente, e por outro mostra o resultado dessa mesma luta pela demarcação dos assentamentos, permitindo ao Estado um maior controle burocrático nesses territórios, e consequentemente nas Escolas do Campo do MST.

\section{REFLEXÕES FINAIS}

A disputa político-institucional e organizacional-pedagógica entre o MST e o Estado se move em distintas dimensões nas E. I., como política pública. Nessa disputa, o MST luta por manter a autonomia político-pedagógica e organizacional não somente nas E. I., mas também nas Escolas Públicas quando o acampamento passa a ser assentamento, espaço onde os poderes estatais tentam fragmentar a realidade escolar fundada na vida da comunidade, pelo caráter da divisão política entre estado federado e município. No mesmo assentamento, uma escola estadual e uma municipal. Essa condição de inserção políticoinstitucional das escolas do MST pode tornar mais difícil a conquista de suas reivindicações. A circunstância da fragmentação institucional na realidade escolar parece ter uma correspondência no processo da reestruturação recente do INCRA, que descentralizará as atividades relacionadas à Reforma Agrária em direção a outros órgãos federais e municipais (PINASSI, FIRMIANO, 2013). Essa mudança terá como resultado uma fragmentação das demandas dos assentamentos e requererá maiores esforços de luta por parte do MST.

Dessa luta pela E.I., no processo histórico de conquista de uma maior autonomia das escolas do MST no Paraná, a partir do ano 2000, o Setor Educacional do Movimento, constando o avanço da formação dos acampados e assentados, outra luta para demandar das Universidades Estaduais a criação e abertura de cursos de formação em nível de graduação e especialização para os professores do MST. Esse processo, que ocorreu por um grupo reduzido de professores universitários, sintonizados com a luta política dos movimentos de luta pela terra, de um lado e as lideranças do Movimento de outro, com todas as dificuldades e preconceitos de ambos os lados, resultou em um primeiro momento (2004), depois de quase dois anos de reuniões, no início da primeira turma do Curso de Pedagogia de Educadores do Campo, no campus de Francisco Beltrão da Universidade Estadual do Oeste do Paraná ${ }^{28}$.

Essa e todas as outras estratégias do MST apresentadas buscam conceituar melhor a Educação do Campo e aprofundar a apropriação crítica do conhecimento orientando-o para sua causa $^{29}$, e insistentemente tentam abrir caminhos para enfrentar o avanço da penetração do modelo de capitalismo agrário, baseado no agronegócio concentrado fortemente no estado do Paraná.

\section{REFERÊNCIAS}

ASSOCIAÇÃO DE COOPERATIVA AGRÍCOLA E REFORMA AGRÁRIA DO PARANÁ Relatório Final. Escola Itinerante dos Acampamentos no Paraná. Curitiba, MST, 2013. 
BAHNIUK, Caroline; CAMINI, Isabela (2012). Escola Itinerante, In: CALDART, Roseli Salete et al (org.). Dicionário de Educação do Campo. Rio de Janeiro/São Paulo: Escola Politécnica de Saúde Joaquim Venâncio (EPSJV/FIOCRUZ)/Expressão Popular. p. 333339.

BRASIL . Constituição da República Federativa do Brasil, art. 206, inciso 1. 14. ed., São Paulo: Atlas, 1999. p. 165.

Lei de Diretrizes e Bases da Educação Nacional. ed São Paulo: Cortez, 1997. p. 96.

Conselho Nacional de Educação. Resolução CNE/CP, 1, de 18 de fevereiro de 2002. Institui diretrizes curriculares nacionais para a formação de professores da educação básica, em nível superior, curso de licenciatura, de graduação plena. 2002. Portal MEC. Disponível em: <http://portal.mec.gov.br/cne/arquivos/pdf/CP012002.pdf >. Acesso em: 12 de maio de 2013.

CALDART, Roseli Salete. Pedagogia do Movimento Sem Terra. São Paulo: Expressão Popular. 2004. p. 236-291.

CALDART, Roseli Salete et al (org.). Dicionário da Educação do Campo. Rio de Janeiro/São Paulo: Escola Politécnica de Saúde Joaquim Venâncio (EPSJV/FIOCRUZ)/Expressão Popular. 2012a. p. 259-260.

Dicionário da Educação do Campo. Rio de Janeiro/São Paulo: Escola Politécnica de Saúde Joaquim Venâncio (EPSJV/FIOCRUZ)/Expressão Popular. 2012b. p. 264.

FACCIN WEIDE, Darlan. A Escola Itinerante em acampamentos de Reforma Agrária no RS. Cadernos da Escola Itinerante - MST, ano 2, n. 3, p. 9-26, 2009.

GEHRKE, Marcos y Maria Isabel Grein. Escola Itinerante no desafio da luta pela Reforma Agrária. Cadernos da Escola Itinerante-MST, v. 1, n. 2, p. 87-96, out. 2008..

JUNGEMANN, Beate. Organizaciones sociales y anclaje socioterritorial. Escenarios y componentes de la transformación socioterritorial y local en Venezuela. Cuadernos del Cendes, Revista da Universidad Central de Venezuela, Caracas, VE, :, n. 67, p. 1-34, 2008.

KNOPF, Jurema de Fatima (2013). A relação entre o MST/PR e o governo Roberto Requião: análise da política da escola itinerante (2003-2010). Dissertação (Mestrado em Educação) - Universidade Estadual do Oeste do Paraná, Cascavel, 2013. Mimeografado.

MANÇANO, Fernandes Bernardo; STÉDILE João Pedro . Brava Gente: la lucha de los Sin Tierra en Brasil. Bogotá, 2003, p. 279.

MORISSAWA , Mitsue. A história da luta pela terra e o MST. São Paulo: Expressão Popular, 2001. p. 255. 
MST. Escola itinerante do MST: história, projeto e experiências. Cadernos da Escola Itinerante-MST, v. 8, n. 1, p. 86, 2008a.

Itinerante: a escola dos Sem Terra - trajetórias e significados. Cadernos da Escola Itinerante - MST, v. 1, n. 2, p. 100, 2008b.

Os desafios da luta pela Reforma Agrária Popular e do MST no atual contexto. Caderno de Debates, n. 1, p. 4, 2009.

MST /PR e SEED. Pesquisas sobre a Escola Itinerante: refletindo o movimento da escola. Cadernos da Escola Itinerante. Ano 2, n. 3, p. 140, 2009.

PARANÁ. Conselho Estadual de Educação . Parecer 1012/2003. Aprova a proposta pedagógica das Escolas Itinerantes para acampados do Movimento dos Trabalhadores Rurais Sem-Terra do Estado do Paraná, com vistas à continuidade da experiência pedagógica ofertada. p. 3.

Secretaria Estadual de Educação . Resolução 614/2004. Autoriza a Implantação da Escola Itinerante nos acampamentos do Movimento dos Trabalhadores Rurais Sem-Terra, que terá como mantenedor o Governo do Estado do Paraná e como Escola Base o Colégio Estadual Iraci Salete Strozak - Ensino Fundamental e Médio, do NRE de Laranjeiras do Sul, a partir do ano letivo de 2004. Diário Oficial [do] Estado do Paraná, Poder Executivo, Curitiba, PR, $\mathrm{n}^{\mathrm{o}}$. 6683, de 9 de Março de 2004. Disponível em: <http://www.legislacao.pr.gov.br/legislacao/pesquisarAto.do?action=exibir\&codAto=6938 7\&indice $=1 \&$ totalRegistros=1>. Acesso em: 15 de maio de 2013 .

Secretaria Estadual de Educação . Resolução 1660/2004. Autoriza o funcionamento da educação Infantil e do Fundamental de $1^{\circ}$ a $4^{\circ}$ série, no Colégio Estadual Iraci Salete Strozak Ensino Fundamental e Médio Localizado no Assentamento Marcos Freire, no Município de Rio Bonito do Iguaçu. Disponível em: $<$ http://www.legislacao.pr.gov.br/legislacao/pesquisarAto.do?action=exibir\&codAto=6938 5\&indice $=1 \&$ totalRegistros=1>. Acesso em: 20 de jun. de 2013 .

PINASSI, Maria O.; Frederíco Daia Firmiano. El MST, la reforma agraria y el neodesarrollismo. [Correio da Cidadania]. Portal de noticias Rebelión. . 15 de agosto 2013. Disponível

em: $<$ http://www.rebelion.org/mostrar.php?dia=15\&mes=08\&ano=2013\&submit=Buscar\&inic io $=0 \&$ tipo $=2>$ e em:

<http://www.rebelion.org/noticia.php?id=172543>. Acesso em: 15 de ago. de 2013.

SAPELLI, Marlene Lucia Siebert . Escola do Campo - espaço de disputa e de contradição: análise da proposta pedagógica das escolas itinerantes do Paraná e do Colégio Imperatriz Dona Leopoldina. Tese (Doutorado em Educação) - Universidade Federal de Santa Catarina, Florianópolis, 2013. Mimeografado. p 67-89.

STURBIN, Florencia. Una experiencia alternativa de Educación Pública: el Movimiento de los Trabajadores Rurales Sin Tierra. In: GENTILI, Pablo e SVERDLICK, Ingrid. Movimientos Sociales y Derecho a la Educación. Cuatro estudios. Buenos Aires, LPPLaboratoria. 2008. p. 135-198. 
TEIXEIRA DE OLIVEIRA, Lia Maria e CAMPOS, Marília . Educação Básica do Campo, In: CALDART, R. et al (org.), Dicionário de Educação do Campo. Rio de Janeiro/São Paulo: Escola Politécnica de Saúde Joaquim Venâncio (EPSJV/FIOCRUZ)/Expressão Popular. 2012. p. 239-246.

VERDÉRIO, Alex . A materialidade da educação do campo e sua incidência nos processos formativos que a sustentam: uma análise acerca do curso de Pedagogia da Terra na Unioeste. Dissertação (Mestrado em Educação) - Universidade Estadual do Oeste do Paraná, Cascavel, 2011. Mimeografado.210 p.

VERGARA-CAMUS, Leonardo. Globalización, tierra, resistencia y autonomía: el EZLN y el MST. Revista Mexicana de Sociología, v. 73, jul./sept.. 2011. p. 10.

\section{FONTES - LEGISLAÇÃO PARANÁ:}

http://www.educadores.diaadia.pr.gov.br/modules/conteudo/

conteudo.php?conteudo $=564$

Notas ${ }^{1}$ Esta comunicação é resultado da primeira etapa do projeto de pesquisa: “O Movimento dos Trabalhadores
Rurais Sem Terra (MST): entre autonomia e institucionalização", desenvolvido por Jungemann e Nogueira,
2012 a 2014.

2 Prof $^{\mathrm{a}}$ Dra. Beate Jungemann CENDES/Universidad Central de Venezuela. Contato: bjungemann@gmail.com.

${ }^{3}$ Prof ${ }^{a}$ Dra. Francis Mary Guimarães Nogueira Unioeste, Universidade Estadual do Oeste do Paraná, Brasil. Contato: guimanog@terra.com.br.

4 “O surgimento da expressão "Educação do Campo" pode ser datado. Nasceu primeiro como Educação Básica do Campo no contexto de preparação da I Conferência Nacional por uma Educação Básica do Campo, realizada em Luziânia, Goiás, de 27 a 30 de julho 1998. Passou a ser chamada Educação do Campo a partir das discussões do Seminário Nacional realizado em Brasília de 26 a 29 de novembro 2002, decisão posteriormente reafirmada nos debates da II Conferência Nacional, realizada em julho de 2004. As discussões de preparação da I Conferência iniciaram-se em agosto de 1997, logo após o I Encontro Nacional dos Educadores e Educadoras da Reforma Agrária (ENERA), realizado pelo Movimento dos Trabalhadores Rurais Sem Terra (MST) em julho daquele ano, evento em que algumas entidades desafiaram o MST a levantar uma discussão mais ampla sobre a educação no meio rural brasileiro" (CALDART et al., 2012a, p. 259-260).

${ }^{5}$ Caldart destaca 3 momentos no processo de ressignificação da escola rural em direção à escola do MST: 1 . A luta pela escola como parte da luta pela terra; 2. A inserção da escola na organização de massas; e 3. A escola do MST e a formação dos sujeitos de um projeto popular de educação e do país (CALDART, 2004, p. 236-291).

${ }^{6}$ Refere-se em primeiro lugar ao Instituto Nacional de Colonização e Reforma Agrária (INCRA) e à Companhia Nacional de Abastecimento (CONAB), bem como à criação de um instituto público de assistência técnica pública e gratuita para as famílias campesinas orientando em direção ao um novo modelo de agricultura baseado na agroecologia (MST, 2009, p. 4).

${ }^{7}$ Para a compreensão histórico-política detalhada desse momento histórico no Brasil, ler Maria Helena Moreira Alves em seu livro "Estado e Oposição no Brasil. 1964-1984".

${ }^{8} \mathrm{Na}$ Dissertação de Alex Verdério, “A materialidade da Educação do Campo e sua incidência nos processos formativos que a sustentam: uma análise acerca do curso de Pedagogia da Terra na UNIOESTE. 2011, se discute com maior aprofundamento a história da emergência do MST. 


\footnotetext{
${ }^{9}$ Todos os dados da ocupação de terra no estado do Paraná entre os anos de 1980 e 1990 estão apresentados e analisados em Sapelli (2013, p. 67-89).

${ }^{10}$ Em 1987, o MST teve seu Primeiro Encontro Nacional de Professores de Assentamentos, que antecedeu a criação do Setor de Educação do Movimento. Desde 1988, este Setor está formalmente lutando pelo direito à educação dos Sem Terra (STURBIN, 2008, p. 135-198). O Encontro Nacional de Educadores e Educadoras da Reforma Agrária (ENERA), realizado pelo MST em 1997 forneceu reflexões importantes para a discussão na I Conferência Nacional por uma Educação Básica do Campo, realizada em 1998 em Goiás. A partir do Seminário Nacional de Educação do Campo de Brasília em 2002, o termo assumiu sua acepção geral (CALDART, 2012, p. 259-260).

${ }^{11}$ Segundo o Censo de 1980, 32\% da população brasileira vivia no campo. Hoje esta população representa ainda 15\% segundo o Censo de 2010 (TEIXEIRA DE OLIVEIRA, CAMPOS, 2012, p. 239-246).

${ }^{12}$ Sobre a ressignificação da Educação Rural ver também Alex Verdério, UNIOESTE. 2011.

${ }^{13}$ Usaremos daqui em diante também a abreviação E. I. quando nos referirmos à Escola Itinerante.

${ }^{14}$ As denominadas "escolas de acampamento" foram as primeiras experiências escolares do MST, desenvolvidas nos primeiros acampamentos de Encruzilhada Natalino e da Fazenda Annoni no estado do Rio Grande do Sul (BAHNIUK, CAMINI, 2012, p. 333-339).
}

${ }^{15}$ O MST conta com dois níveis de Coletivos de Educação, um a nível nacional e outro a nível estadual. A instância nacional é composta pelos Coletivos Estaduais e tem o objetivo geral de lutar para que o Estado cumpra o direito de acesso à educação nos acampamentos e assentamentos; registra as experiências acumuladas das E. I.; orienta os coletivos estaduais e forma os militantes. Por outro lado, a instância estadual entre direto em disputa com as Secretarias de Educação do Estado em relação às E. I. Além disso, se ocupa da organização da formação contínua dos educadores das E. I. (SAPELLI, 2013).

${ }^{16} \mathrm{O}$ fomento das E. I. nos acampamentos no estado do Paraná, a decisão do MST de sistematizar as experiências em curso e publicar os resultados assim como o método de trabalho no Setor de Educação do Movimento baseados em contínuos encontros de formação e de reflexão, assim como a inserção de educadores do MST na UNIOESTE, levaram à produção de muitos trabalhos acadêmicos de graduação e de pós-graduação sobre o tema das Escolas Itinerantes.

${ }^{17}$ Houve dois massacres que marcaram essa época: o massacre de Curumbiara, no estado de Rondônia, em 1995, onde morreram 9 membros do MST, e o massacre de Eldorado de Carajá, no estado do Pará, em 1996, onde foram assassinados 19 integrantes dos Sem Terra.

${ }^{18} \mathrm{O}$ processo de institucionalização das E. I. e suas contradições será abordado no item 3 .

${ }^{19}$ No ano de 2004, existiam oficialmente 6 E. I., sendo que esse número aumentou para 11 em 2006 (KNOPF, 2013). Somente duas dessas escolas ofereceram o Ensino Médio, o restante se limitava ao Ensino Fundamental. No ano de 2013, existiam 9 E. I., das quais algumas ofereciam desde a Educação Infantil até o Ensino Médio, outras somente até o Ensino Fundamental. No total, estudavam esse ano 1.064 alunos do MST nas E. I. dôo Paraná (MST, 2008b; SAPPELLI, 2013).

${ }^{20}$ Segundo entrevistas realizadas pelas autoras em setembro de 2012 a pessoas acampadas, as famílias estão organizadas em núcleos de base (10 famílias formam um núcleo); cada núcleo é um grupo representado por um coordenador e uma coordenadora; 50 famílias formam uma brigada que está representada por 2 dirigentes (um homem e uma mulher) e tem um responsável para diferentes setores (saúde, educação, alimentação, higiene, finanças, comunicação, gênero etc.). Os setores estão representados no âmbito regional e estadual. Dessa maneira, se amplia a representação da base nas instâncias territoriais, o que possibilita uma maior participação sobre as realidades nos acampamentos. As entrevistas mostram a grande importância que tem para a construção das relações comunitárias a rotação de responsabilidades nessa estrutura organizativa assumida pelas pessoas. Especialmente, as mulheres atravessam um processo de autoestima muito reconhecido.

${ }^{21}$ Os resultados do estudo de Sapelli (2013) e os da Associação de Cooperação Agrícola e Reforma Agrária do Paraná (ACAP, 2013) mostram limitações de diferentes índoles na operacionalização do projeto político pedagógico das E. I. do estado do Paraná. Entre estas se encontram a insuficiente preparação e participação da comunidade no desenvolvimento do projeto, as dificuldades de professores internos do MST em aplicar a metodologia e os instrumentos adequadamente e a resistência dos professores externos que trabalham nas E. 
I. de sair de sua rotina e costume dos conceitos pedagógicos, didáticos, curriculares e avaliativos aprendidos e exigidos nas escolas públicas tradicionais.

${ }^{22}$ Entrevistas em diferentes acampamentos mostram que os seguintes fatores são valorizados como fundamentais para um ambiente e desenvolvimento positivo de socialização das crianças e dos jovens e de convivência familiar e coletiva: a rejeição à violência e ao consumo de drogas e, por conseguinte, a segurança, a solidariedade, a confiança, assim como a integração da escola à vida comunitária e vice-versa.

${ }^{23}$ Nos acampamentos convivem campesinos, filhos de campesinos, habitantes de favelas de grandes cidades, imigrantes, sobretudo, do Paraguai, alguns vivem em acampamentos há anos, outros não, alguns passaram por situações de violência e despojo, outros não (GEHRKE, GREIN, 2008, p. 87-96). Informações sobre a história de colonização e de imigração do estado do Paraná no marco dos projetos de desenvolvimento se encontram em Sapelli (2013).

${ }^{24}$ Muitos homens e também mulheres do MST têm que vender sua força de trabalho fora dos acampamentos para obter alguma renda. Trabalham por dia, como ajudantes de pedreiros, em serviços domésticos etc. Dentro do acampamento plantam para assegurar a alimentação de sua família (entrevista das autoras a integrantes de acampamentos e SAPELLI, 2013, p. 67-89).

${ }^{25}$ O PPP questiona os fundamentos da escola capitalista. Organiza-se por ciclos de formação humana rompendo com a lógica de tempos homogêneos de desenvolvimento e de aprendizagem; o sistema de avaliação não é punitivo expresso em notas, mas em avaliações escritas contínuas e discutidas em Conselhos Participativos de Classe entre professores, pais e alunos. Nas E. I. do Paraná estão começando a se incorporar elementos da pedagogia socialista baseada nos pioneiros teóricos da educação da escola soviética (Pistrak, Krupskaya, Shulgin e outros). Isso significa passar dos "temas geradores" de Paulo Freire aos "complexos de estudo" (BAHNIUK, CAMINI, 2012, p. 333-339).

${ }^{26}$ Esse programa vem executando, depois do governo Lula, políticas de educação em todos os níveis e modalidades de ensino em várias áreas da Reforma Agrária mediante a participação entre universidades, movimentos sociais e o governo federal por meio do Instituto Nacional de Colonização e Reforma Agrária (INCRA).

${ }^{27}$ A Escola Base à qual devem estar associadas todas as E. I. é uma escola da Rede Pública de Educação do estado do Paraná. Ela foi criada em 2003 com a finalidade de "acompanhar e dar suporte legal e pedagógico a vida escolar dos educandos/as e educadores/as nos acampamentos" (MST, 2008b, p. 100). O Colégio Estadual Iraci Salete Strozak está localizado no Assentamento Marcos Freire, município de Rio Bonito de Iguaçu.

${ }^{28}$ O curso foi coordenado pelo Grupo de Pesquisas em Políticas Públicas (GPPS) da UNIOESTE, campus de Cascavel, com a participação de professores dos campi de Francisco Beltrão, Toledo, Marechal Cândido Rondon e Foz do Iguaçu. Posteriormente, outras universidades estaduais se envolveram, a Universidade Estadual do Centro-Oeste (UNICENTRO) e a Universidade Estadual de Maringá (UEM).

29 "Cerca de 350 mil integrantes do MST já frequentaram cursos de alfabetização, ensino fundamental, ensino médio, superior e cursos técnicos. Por ano, há aproximadamente 28 mil educandos e 2 mil professores comprometidos com o processo educacional. Destacamos o papel da educação agroecológica, em associação com universidades públicas (são 5 mil educandos nessas instituições) e com a Escola Nacional Florestan Fernandes, que, desde 2005, vem recebendo militantes do próprio MST e de outros movimentos sociais do Brasil, da América Latina e do mundo inteiro" (PINASSI, FIRMIANO, 2013, p. 4).

Recebido: $\quad$ março-16 $\quad$ Aprovado: $\quad$ setembro-16 